Reply to Letter to the Editor

\title{
Response to "How much does the Addiction-Like eating behaviour scale add to the debate regarding food versus eating addictions?"
}

International Journal of Obesity (2018) 42, 947-948; doi:10.1038/ ijo.2017.291

We thank Schulte, Potenza, and Gearhardt for their response to our recent publication (The development and validation of the Addiction-like Eating Behaviour Scale;AEBS). The AEBS quantifies individual differences in core behavioural processes that characterize overeating, and which are similar to the processes underpinning drug/alcohol use and other compulsive behaviours. This is distinct from the Yale Food Addiction Scale (YFAS) which is based on the DSM substance-use disorder criteria ${ }^{1,2}$. However, as Schulte et al. point out, both the AEBS and YFAS incorporate behavioural criteria and this is consistent with the general assessment of addictive disorders (substance-based and behavioural).

With regard to the distinction between substance-based and behavioural addictions, Schulte et al. suggest that the AEBS is consistent with a substance-based framework due to the inclusion of items referring to problematic intake of 'high fat/ sugar' foods. We contest this view and point out that these items refer to general types of food, rather than a specific ingredient (as a substance-based framework would predict). This is consistent with evidence that people experience problems controlling their intake of a range of energy-dense foods ${ }^{3,4}$. This implies that there is not a specific addictive ingredient in foods but rather it is the high-energy density of such foods which makes them highly desired. Notably, a recent study found that YFAS symptoms were more closely related to the overconsumption of foods high in fat and sugar (i.e. energy-dense foods), than to foods high in sugar alone ${ }^{5}$.

Schulte et al. also suggest that a move away from the DSM criteria for addictive disorders limits the validity of the AEBS as a measure of addiction. However, given fundamental differences between drugs and food ${ }^{4,6}$, we suggest that moving away from the DSM criteria is necessary to develop a valid framework for assessing addiction-like eating. Our approach led to the development of a scale which is entirely consistent with theoretical perspectives on addiction. Specifically, the two-factor structure of the AEBS (appetitive drive/dietary control) reflects well-established dual-process models of addictive disorders and overeating ${ }^{7,8}$ (i.e. increased reward responsivity/diminished inhibitory control). Furthermore, individual scale items of the AEBS correspond with core features of addictive disorders (e.g. loss of control, preoccupation, negative consequences) $)^{9}$. It is also important to note that the AEBS provides a continuous measure of individual differences in addition-like eating, and was not intended as a diagnostic tool for 'eating-addiction'.

Finally, Schulte et al. suggest that the behavioural eating addiction vs. food addiction debate detracts from key issues surrounding the concept of addiction-like eating. However, we suggest that such issues can only be addressed following careful consideration of how addiction-like eating should be defined. The AEBS provides a means to assess addiction-like eating behaviour in a way that reflects validated models of motivated behaviour. We agree with Schulte et al. that establishing the distinction between food addiction and binge eating is a key area for future research ${ }^{10}$. The AEBS may help to address this; indeed, the scale was able to predict variance in BMI beyond that accounted for by a measure of binge eating. We therefore envisage that the AEBS will have important implications for establishing the clinical utility of addiction-like eating, and enabling the development of personalised treatments for overeating and obesity.

\section{CONFLICT OF INTEREST}

The authors declare no conflict of interest.

\section{ACKNOWLEDGEMENTS}

The material is original, has not been previously published and has not been submitted for publication elsewhere while under consideration.

HK Ruddock ${ }^{1}$, P Christiansen ${ }^{1,2}$, JCG Halford ${ }^{1}$ and CA Hardman ${ }^{1}$

${ }^{1}$ School of Psychology, University of Birmingham, Birmingham, UK and

${ }^{2}$ UK Centre for Tobacco and Alcohol Studies, UK E-mail: h.k.ruddock@bham.ac.uk

\section{REFERENCES}

1 Gearhardt AN, Corbin WR, Brownell KD.. Preliminary validation of the Yale food addiction scale. Appetite 2009; 52: 430-436.

2 Gearhardt AN, Corbin WR, Brownell KD.. Development of the Yale food addiction scale version 2.0. Psychol. Addict Behav. 2016; 30: 113-121.

3 Ruddock HK, Dickson JM, Field M, Hardman CA. Eating to live or living to eat? Exploring the causal attributions of self-perceived food addiction. Appetite 2015; 95: 262-268.

4 Rogers PJ.. Food and drug addictions: Similarities and differences. Pharmacol. Biochem. Behav. 2017; 153: 182-190.

5 Markus CR, Rogers PJ, Brouns F, Schepers R.. 'Eating dependence and weight gain; no human evidence for a 'sugar-addiction' model of overweight'. Appetite 2017; 114: 64-72. 
6 Ziauddeen H, Farooqi IS, Fletcher PC.. Obesity and the brain: how convincing is the addiction model? Nat Rev Neurosci 2012; 13: 279-286.

7 Wiers RW, Bartholow BD, van den Wildenberg E, Thush C, RCME Engels, Sher KJ et al. Automatic and controlled processes and the development of addictive behaviors in adolescents: a review and a model. Pharmacol. Biochem. Behav. 2007; 86: $263-283$.

8 Nederkoorn C, Houben K, Hofmann W, Roefs A, Jansen A.. Control yourself or just eat what you like? Weight gain over a year is predicted by an interactive effect of response inhibition and implicit preference for snack foods. Health Psychol. 2010; 29: 389-393.

9 Sussman S, Sussman AN.. Considering the definition of addiction. Int. J. Environ. Res. Public Health 2011; 8: 4025-4038.

10 Davis C.. A commentary on the associations among 'food addiction', binge eating disorder, and obesity: Overlapping conditions with idiosyncratic clinical features. Appetite 2016; 115: 3-8.

cC) (i)

This work is licensed under a Creative Commons Attribution 4.0 International License. The images or other third party material in this article are included in the article's Creative Commons license, unless indicated otherwise in the credit line; if the material is not included under the Creative Commons license, users will need to obtain permission from the license holder to reproduce the material. To view a copy of this license, visit http://creativecommons.org/licenses/ by/4.0/

(c) The Author(s) 2018 